\title{
Waste to Worth - Sludge Containing Calcium Carbonate into Useful Building Materials - an Indian Context
}

\author{
Varinder S Kanwar* \\ Vice-Chancellor, Chitkara University, Himachal Pradesh, India
}

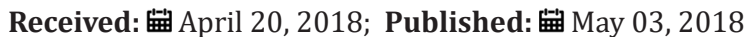

*Corresponding author: Varinder S Kanwar, Vice-Chancellor, Chitkara University, Himachal Pradesh, India, Email: vc@chitkarauniversity.edu.in

\section{Opinion}

Human activities on earth produce in considerable quantities of wastes more than 2,500 million tons per year, including industrial and agricultural wastes from rural and urban societies. This creates serious problems to the environment, health and also the land filling. Now a day the concrete and bricks are most used man made materials in the world. The Indian construction industry alone consumes approximately 400 million tons of concrete every year and the relative amount of bricks too. Therefore the demand of the concrete, bricks and the required raw materials are very high. This causes the hike in the costs and demand of cement, bricks fine and coarse aggregates. Environmental degradation, high energy consumption and financial constraints has forced various organizations in India and abroad to recommend various qualitative guidelines for generation, treatment, handling, transport, disposal and recycling of non-hazardous and hazardous wastes. On the other side due to exponential growth of population in recent years, there is great demand for construction and thus increasing pressure for use of natural resources causing their acute shortage. There is environmental problem due excessive use of topsoil in brick manufacturing. Natural materials being exhaustible in nature, its quantity is declining gradually. Also, cost of extracting good quality of natural material is increasing. Concerned about this, the

scientists are looking for alternative materials for construction, and industrial waste product is one such category. If these materials can be suitably utilized in construction, the pollution and disposal problems can be partly reduced. It is now a global concern, to find a social, techno-economic, environmental friendly solution to sustain a cleaner and greener environment. In recent years, the utilization of solid waste is the challenge for the civil and environmental engineers to utilize economic friendly supplementary cementitious materials produced at reasonable cost with the low possible environmental impact. Some of the researchers successfully tested and used industrial wastes such as blast furnace slag, fly ash etc. which offers benefits like potential savings in natural resources and energy, reduction in impact of $\mathrm{CO} 2$ emission, and re-use of wastes which otherwise would have been used as landfill and might require a waste management program. The Industrial systems are linear systems taking in raw material and giving out products and wastes. In their effort to minimize negative impact on environment, industries have been traditionally collecting and treating the wastes before disposal. This approach i.e. end-of-pipe approach, to wastes has been resulting in the removal of pollutants from one medium and placing in some other medium rather than ending the cycle of wastes, leading to the wasteful spending of resources. Further waste management by this approach is proving to be a burden on the industry. The magnitudes of limitations associated with end-ofpipe approach have recently been forcing the industries to examine this approach critically and adopt an alternative waste handling approach. Waste handling approach is leading to environment friendly technology and processes. Itintegrates both waste reduction approach and end-of-pipe treatment approach. In India around 1000 million tonnes of solid waste is being generated annually as by-products during industrial, mining, municipal, agricultural, and other processes. Out of this about 300 million tonnes is inorganic waste-nonhazardous and hazardous. Industrialization in India has no doubt helped in economic growth of our country but at the same time it also increases the pollution problem manifold. Environmental conservation is an indisputable industrial responsibility, and market competitiveness has demanded proactive and concrete actions from industry to preserve the environment. This demand promotes the minimisation of environmental impacts through the use of clean technologies that minimise waste generation and maximise reuse. The use of such technologies leads to the utilisation of wastes, energy savings and other gains. Lot of studies have been done for utilisation of this waste specific to the properties of the waste as building materials. To build sustainable environment and to meet the demand of construction material it is 
very important to find the link between waste generating industries and construction industry. Our toothpaste industry sector is presently facing the problems of safe disposal of solid waste. The very feature of toothpaste industry waste is that it contains $\mathrm{CaCo}_{3}$ in abundance; attracts the attentions of Civil Engineers. The author has developed a technology for utilizing waste from toothpaste industry as an alternative to virgin materials and building products. It is very much possible to manufacture good quality of clay bricks, concrete and hard grade bitumen by blending some amount of this sludge, thus solving issue of waste disposal and producing a low cost environmental friendly building material.

\section{(c) \\ This work is licensed under Creative \\ Commons Attribution 4.0 License}

To Submit Your Article Click Here:

DOI: 10.32474 /TCEIA.2018.02.000131

Submit Article

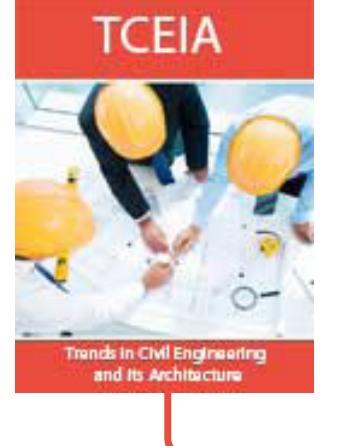

Trends in Civil Engineering and its Architecture

\section{Assets of Publishing with us}

- Global archiving of articles

- Immediate, unrestricted online access

- Rigorous Peer Review Process

- Authors Retain Copyrights

- Unique DOI for all articles 